\title{
Lasting reduction of severe spasticity after ending chronic treatment with intrathecal baclofen
}

\author{
Jürgen Dressnandt, Bastian Conrad
}

\begin{abstract}
Objective-To investigate whether the dose of intrathecal baclofen necessary for a sufficient reduction of muscle tone and spasms changes during treatment of severe spasticity.

Methods-A group of 27 patients received intrathecal baclofen for 61 (SD 18) months.

Results-Spasticity remained absent or strongly reduced after stopping the intrathecal baclofen infusion in seven patients. The dose of baclofen could be reduced to $40 \%$ of that dose which was originally necessary in 10 patients. The dose remained the same or increased slightly in 10 patients. Possible reasons for the continuing reduction of spasticity after terminating long term intrathecal baclofen infusion in some patients could be: lasting morphological changes in spinal cord neurons by second messenger controlled modulation of gene expression, a toxic effect of baclofen on spinal neurons, muscular atrophy, inflammation due to the catheter, or progression of multiple sclerosis.

Conclusions-A higher initial daily dose of intrathecal baclofen might lead to a faster, lasting suppression of spasticity and the development of spastic symptoms might even be prevented by pre-emptive treatment with baclofen in patients with newly acquired lesions of the spinal cord.
\end{abstract}

$(尹$ Neurol Neurosurg Psychiatry 1996;60:168-173)

Keywords: intrathecal baclofen; spasticity

For a decade severe forms of spasticity have been successfully treated with intrathecal infusion of baclofen. ${ }^{1-4}$ Many authors have reported the necessity of increasing the daily dose of baclofen within the first year of treatment $^{356}$; this stabilises thereafter. After a bolus of baclofen the increased muscle tone disappears within 40-90 minutes and reappears after four to six hours. ${ }^{17} \mathrm{~A}$ reappearance of spasticity has also been described after interruption of long term treatment with intrathecal baclofen. ${ }^{7}$ We found that some patients treated for several years did not require intrathecal baclofen treatment any more and in other patients the dose necessary for sufficient suppression of spastic symptoms could be reduced appreciably. These patients are described and hypothetical mechanisms are discussed. Some of this data has been presented previously. ${ }^{8}$

\section{Patients and methods}

Patients with severe forms of paraspasticity or tetraspasticity have been treated with continuous intrathecal baclofen at the Department of Neurology of the Technical University of Munich since 1986. The antispastic drug baclofen (racemic solution from Ciba-Geigy) is given into the intrathecal space through a subcutaneous catheter by an implanted programmable pump (Medtronic Synchromed $8611 \mathrm{H})$. The catheter's tip is positioned at the level of the 10th thoracic vertebra. The infusion rate is continuous. During visits to refill the pump, a neurological examination takes place, assessing the muscular tone with the Ashworth scale ${ }^{910}$ and the elicitability of spasms with a spasm scale. ${ }^{5}$ The dose of baclofen is score adjusted (see results section) in accord with a clinical examination and complaints of the patient.

From the patients who had received a pump implant in our department, 27 were followed up for more than two years in our outpatient clinic. In 1991 we found that stopping infusion of intrathecal baclofen did not lead to a reappearance of increased muscle tone in two patients ( 1 and 2$)$. Thereafter we tried to reduce the dose of intrathecal baclofen gradually in those patients who came regularly to have the pump refilled. From the 27 patients, a trial of reduction of the intrathecal baclofen dose has been carried out in 23 . The reduction was done in small steps in the outpatient clinic and in bigger steps if the patients were staying in hospital. We did not try to reduce intrathecal baclofen in patients with tetraspasticity and with a large increase in muscle tone in the upper limbs or in those patients who received a higher dose to reduce central pain.

Up to now intrathecal baclofen infusion has been discontinued in six patients because of dead batteries. In another patient the catheter was prophylactically removed because a decubital ulcer had developed in the route of the catheter.

\section{Results}

It was possible to stop treatment with intrathecal baclofen without the reappearance of spastic symptoms in seven patients out of 27 and to reduce the dose appreciably 
Description of patients, clinical findings, and treatment regimens

\begin{tabular}{|c|c|c|c|c|c|c|c|c|c|c|c|}
\hline Patient & $\begin{array}{l}\text { Age } \\
(y) / \\
\text { sex }\end{array}$ & $\begin{array}{l}\text { Diagnosis/ } \\
\text { duration } \\
\text { until } \\
\text { ith } b(y)\end{array}$ & & Symptom & $\begin{array}{l}\text { Duration } \\
\text { of ith b } \\
\text { (months) }\end{array}$ & $\begin{array}{l}\text { Tonus at } \\
\text { lower limbs } \\
\text { beforelduring/ } \\
\text { after ith b } \\
\text { (Ashworth) }\end{array}$ & $\begin{array}{l}\text { Spasms at } \\
\text { lower limbs } \\
\text { before/during/ } \\
\text { after ith } b\end{array}$ & $\begin{array}{l}\text { Tendon reflexes } \\
\text { (patella) } \\
\text { beforelduring } \\
\text { after ith b }\end{array}$ & $\begin{array}{l}\text { Duration } \\
\text { after } \\
\text { stopping } \\
\text { ith b } \\
\text { (months) }\end{array}$ & $\begin{array}{l}\text { Oral } \\
\text { antispastic } \\
\text { drugs before } \\
\text { ith } b \text { (mg) } \\
\text { (inefficient) }\end{array}$ & $\begin{array}{l}\text { Oral } \\
\text { antispastic } \\
\text { drugs after } \\
\text { ith b (mg) }\end{array}$ \\
\hline 1 & $66 / \mathrm{F}$ & MS & $>11$ & $\mathrm{p}$ & 67 & $4 / 1 / 1$ & $4 / 0 / 1$ & $4 / 0 / 2$ & 24 & $\mathrm{~b} 50 / \mathrm{t} 4$ & $\mathrm{~b} 12 / \mathrm{t} 2$ \\
\hline 2 & $53 / \mathrm{F}$ & MS & 23 & $\mathrm{p}$ & 51 & $4 / 1 / 1$ & $3 / 0 / 0$ & $3 / 0 / 0$ & 6 & b $150 / \mathrm{t} 4 / \mathrm{d} 200$ & None \\
\hline 3 & $47 / \mathrm{F}$ & MS & $>4$ & $\mathrm{t}$ & 58 & $3 / 2 / 2$ & $3 / 1 / 1$ & $4 / 0 / 1$ & 12 & b100 & b25 \\
\hline 4 & $51 / M$ & MSandHT & 11 & $\mathrm{p}$ & 50 & $3 / 2 / 2$ & $3 / 1 / 1$ & $2 / 0 / 1$ & 14 & b100 & None \\
\hline 5 & $74 / \mathrm{F}$ & $\operatorname{tr} \mathrm{T} 7$ & $1 / 2$ & $\mathrm{p}$ & 49 & $4 / 1 / 2$ & $3 / 1 / 2$ & $4 / 1 / 2$ & 5 & b80 & b30 \\
\hline 6 & $74 / \mathrm{F}$ & tu T6 & $1 / 2$ & $\mathrm{p}$ & 56 & $5 / 1 / 1$ & $3 / 0 / 0$ & $5 / 1 / 3$ & 9 & b75 & None \\
\hline 7 & $69 / \mathrm{F}$ & MS & 21 & $\mathrm{p}$ & 94 & $3-4 / 1 / 2$ & $2 / 0 / 2$ & $4 / 1 / 4$ & 6 & b75 & None \\
\hline 8 & 63/M & cer inf & 1 & $\mathrm{t}$ & 79 & $4 / 2 / 2$ & $3 / 2 / 2$ & $3 / 2 / 3$ & 2 & b120 & \\
\hline 9 & $62 / \mathrm{F}$ & MS & 14 & $\mathrm{t}$ & 83 & $4-5 / 1$ & $4 / 0$ & $4 / 2$ & & b100 & \\
\hline 10 & $53 / \mathrm{F}$ & MS & 31 & $\mathrm{p}$ & 25 & $5 / 1$ & $3 / 0$ & $2 / 1$ & & $\mathrm{~b} 40 / \mathrm{d} 150$ & \\
\hline 11 & $57 / \mathrm{F}$ & MS & 13 & $\mathrm{p}$ & 72 & $3-4 / 1$ & $3 / 1$ & $4 / 2$ & & b100 & \\
\hline 12 & $51 / \mathrm{F}$ & MS & 28 & $\mathrm{p}$ & 58 & $4-5 / 1$ & $3 / 2$ & $4 / 1$ & & b75 & \\
\hline 13 & $52 / \mathrm{F}$ & MS & 19 & $\mathrm{p}$ & 35 & $3 / 1-2$ & $2 / 1-2$ & $3 / 2$ & & b75/t12 & \\
\hline 14 & $54 / \mathrm{F}$ & MS & 18 & $\mathrm{t}$ & 99 & $4-5 / 1$ & $4 / 1-2$ & $4 / 1$ & & $\mathrm{~b} 80 / \mathrm{m} 300$ & \\
\hline 15 & $20 / M$ & tu T5 & $1 / 2$ & p & 56 & $5 / 2$ & $4 / 1$ & $2 / 1$ & & $\mathrm{~b} 45 / \mathrm{t} 6$ & \\
\hline 16 & $51 / \mathrm{M}$ & $M S$ & 16 & $\mathrm{t}$ & 88 & $3 / 1$ & $2 / 0$ & $3 / 0$ & & b60/t16 & \\
\hline 17 & $46 / \mathrm{F}$ & MS & 10 & $\mathrm{p}$ & 55 & $5 / 2$ & $4 / 2$ & $4 / 1$ & & b65 & \\
\hline 18 & 19/M & cer inf & $1 / 2$ & $\mathrm{t}$ & 72 & $5 / 2 / 2-3$ & $4 / 1 / 2$ & $4 / 2 / 3$ & 5 & b75/d75 & bloo \\
\hline 19 & $41 / \mathrm{F}$ & MS & 8 & $\mathrm{p}$ & 50 & $5 / 1$ & $2 / 0$ & $3 / 0$ & & b30/t9 & \\
\hline 20 & $51 / \mathrm{F}$ & MS & 7 & $\mathrm{t}$ & 37 & $5 / 1$ & $4 / 0$ & $3 / 0$ & & b90/d50 & \\
\hline 21 & $31 / M$ & tr c6 & 2 & $\mathrm{t}$ & 60 & $4 / 1$ & $4 / 0$ & $5 / 1$ & & b150 & \\
\hline 22 & $41 / M$ & MS & 14 & $\mathrm{t}$ & 61 & $5 / 2$ & $4 / 1$ & $4 / 0$ & & b95/t14 & \\
\hline 23 & $44 / \mathrm{F}$ & MS & 14 & $\mathrm{t}$ & 69 & $5 / 1$ & $4 / 0$ & $5 / 0$ & & b80/t14 & \\
\hline 24 & $38 / \mathrm{M}$ & MS & 10 & $\mathrm{t}$ & 47 & $4 / 1$ & $4 / 1$ & $5 / 1$ & & b100 & \\
\hline 25 & $33 / \mathrm{M}$ & $\operatorname{tr} \mathrm{T} 6$ & 1 & $\mathrm{p}$ & 92 & $3 / 1$ & $4 / 2$ & $4 / 1$ & & b150 & \\
\hline 26 & $49 / \mathrm{F}$ & MS & 23 & $\mathrm{p}$ & 54 & $4 / 1$ & $3 / 1$ & $3 / 1$ & & b20 & \\
\hline 27 & $60 / \mathrm{F}$ & MS & 27 & $\mathrm{p}$ & 62 & $5 / 1$ & $4 / 1$ & $4 / 0$ & & b80/te 100 & \\
\hline
\end{tabular}

MS = Multiple sclerosis; HT $=$ head trauma; tr T7 = spinal trauma at the level of the seventh thoracic vertebra; tu = tumour; cer inf $=$ cerebral infarction; $p=$ paraspasticity; $t=$ tetraspasticity; ith $b=$ treatment with intrathecal baclofen; drugs: $b=$ baclofen, $t=$ tizanidine, $d=$ dantrolene, $m=$ memantine, te $=$ tetrazepam; Ashworth scale: $1=$ no increase in tone, $2=$ slight increase in tone when affected part is moved in flexion or extension, $3=$ more pronounced increase in tone, but affected part easily flexed, $4=$ considerable increase in tone; passive movement difficult, $5=$ affected part rigid in flexion or extension; spasm score: $0=$ no spasms, $1=$ no spontaneous spasms, vigorous sensory or motor stimulation results in spasms, $2=$ occasional spontaneous spasms $<1 / \mathrm{h}$, and easily induced spasms, $3=$ infrequent spontaneous spasms $1-10 / \mathrm{h}, 4=$ spontaneous spasms $>10 / \mathrm{h}$; tendon reflex score: $0=$ absent reflex, $1=$ hyporeflexia, $2=$ normal, $3=$ mild hyperreflexia, $4=3-4$ clonus beats, $5=>4$ clonus beats.

Figure 1 Time course of intrathecal baclofen doses for patients for whom no further intrathecal baclofen infusion was necessary; $P=$ pump failure (battery exhaustion); $C=$ catheter malfunction; bars indicate period during which the filling was done by the general practitioner, who did not have a programmer to change the dose; arrows indicate the time when we became aware that baclofen could be stopped or reduced in some patients. in 10 others. A reduction was mainly possible in those patients who did not have tetraspasticity and who had already been receiving intrathecal baclofen for several years.

PATIENTS WITH NO NEED FOR FURTHER

TREATMENT WITH INTRATHECAL BACLOFEN

After stopping intrathecal baclofen infusion we found a cessation or only a slight increase in spastic symptoms such as muscle tone and spasms in seven patients (1-7; table). These patients had received intrathecal baclofen over a period of 60 (SD 15) months to treat severe paraspasticity or tetraspasticity due to multiple sclerosis (five) or spinal trauma (two). The mean dose of intrathecal baclofen
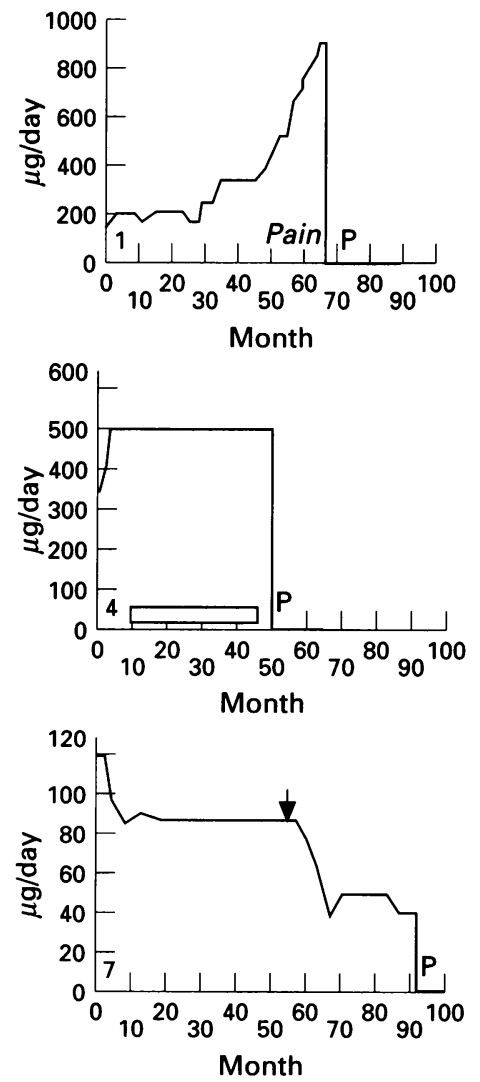
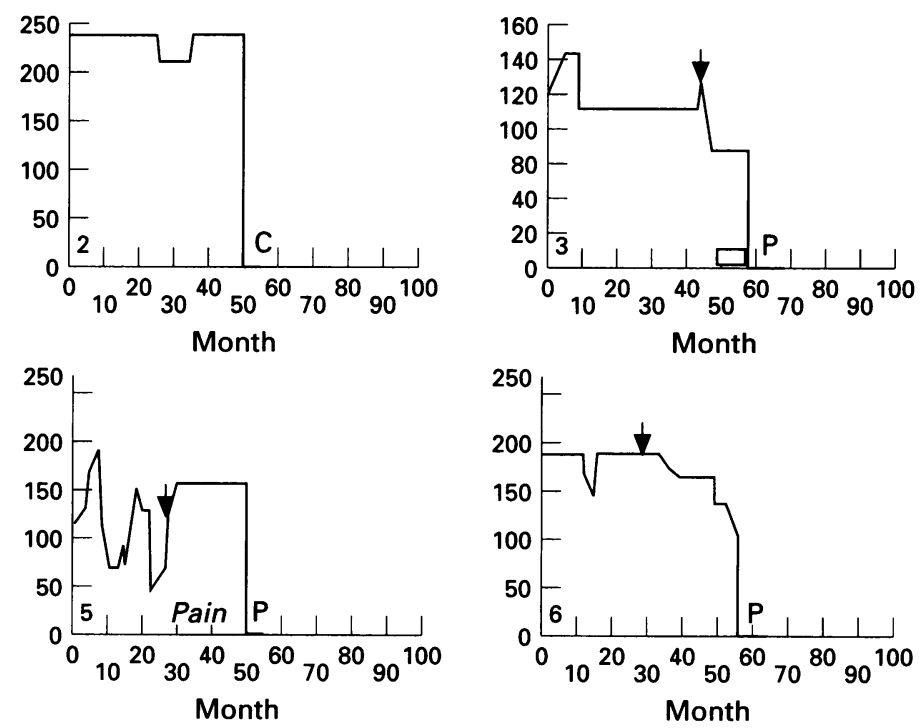
was $189 \mu \mathrm{g} /$ day at the end of the first year of treatment. These patients were followed up for 11 (SD 6) months after stopping the infusion. Figure 1 shows the doses for individual patients.

Patient 1 complained of a burning pain which did not respond to carbamazepine or amitriptyline and therefore we tried, unsuccessfully, to reduce the pain by increasing the intrathecal baclofen dose. This was also the first patient in whom we noted a continuing suppression of muscle tone and spasms after the pump had stopped. In one patient (3), who was tetraspastic, a moderate increase in muscle tone reappeared in the arms and a small increase in the legs after failure of the pump. The increased muscle tone with flexor spasms in the lower limbs, which had initially prompted intrathecal baclofen treatment, did not reappear. In patient 5 the increase in the dose after 17 and 29 months was given because the patient reported pain which did not respond to other analgesics, and it responded only poorly to the increased dose of baclofen. Patient 6 , who became bedridden after the removal of a spinal meningeoma, could walk again three months after intrathecal baclofen infusion was started. A reduction of the dose after 18 months of treatment led to an increase in muscle tone and a worsening of the ambulatory capability and thus the dose was increased again. Three years after beginning treatment with intrathecal baclofen a gradual reduction to $60 \%$ of the initial dose was initiated, after which the pump stopped because of a dead battery. After eight months without intrathecal baclofen and without any other antispastic drugs the gait was as good as during intrathecal baclofen treatment. There was no increase in muscle tone, merely the reappearance of a Babinski's sign.

Two other patients $(8,18)$ are also discussed here. Although they are not specifically members of this group, they are of relevance to it. These patients, both with tetraspasticity, showed no appreciable increase in spasticity (2 on the Ashworth scale) in the lower limbs after stopping the infusion because of battery exhaustion. In patient 8 treatment with intrathecal baclofen was started again to reduce the increased muscle tone in the upper limbs, which had increased to 5 on the Ashworth scale after intrathecal baclofen infusion was interrupted; it was reduced to 3 after the infusion was started again. The dose given after restarting treatment was lower than before the treatment was stopped.

Patient 18 had only moderate spasticity (muscle tone in the arms 3-4, legs 2, spasms in the legs 1) for six months without intrathecal baclofen, but after severe pneumonia there was an increase in spasticity more pronounced in the upper limbs (muscle tone 5) than in the lower ones (muscle tone 3, spasms 4) so that the treatment was restarted (for these patients see figs 2 and 3 ).

\section{PATIENTS IN WHOM APPRECIABLE REDUCTION} OF DOSE WAS POSSIBLE

We reduced the dose of intrathecal baclofen in eight patients with multiple sclerosis, one with cerebral infarction, and one with a spinal
Figure 2 Time course of intrathecal baclofen doses for patients for whom a reduction of the dose was possible. Note that for some patients there was an increase in dose during the first year of treatment with a reduction only thereafter. $I=$ infection; $T=$ tetraspasticity (indicating the start of increased spasticity also in the arms); other abbreviations as fig 1 .
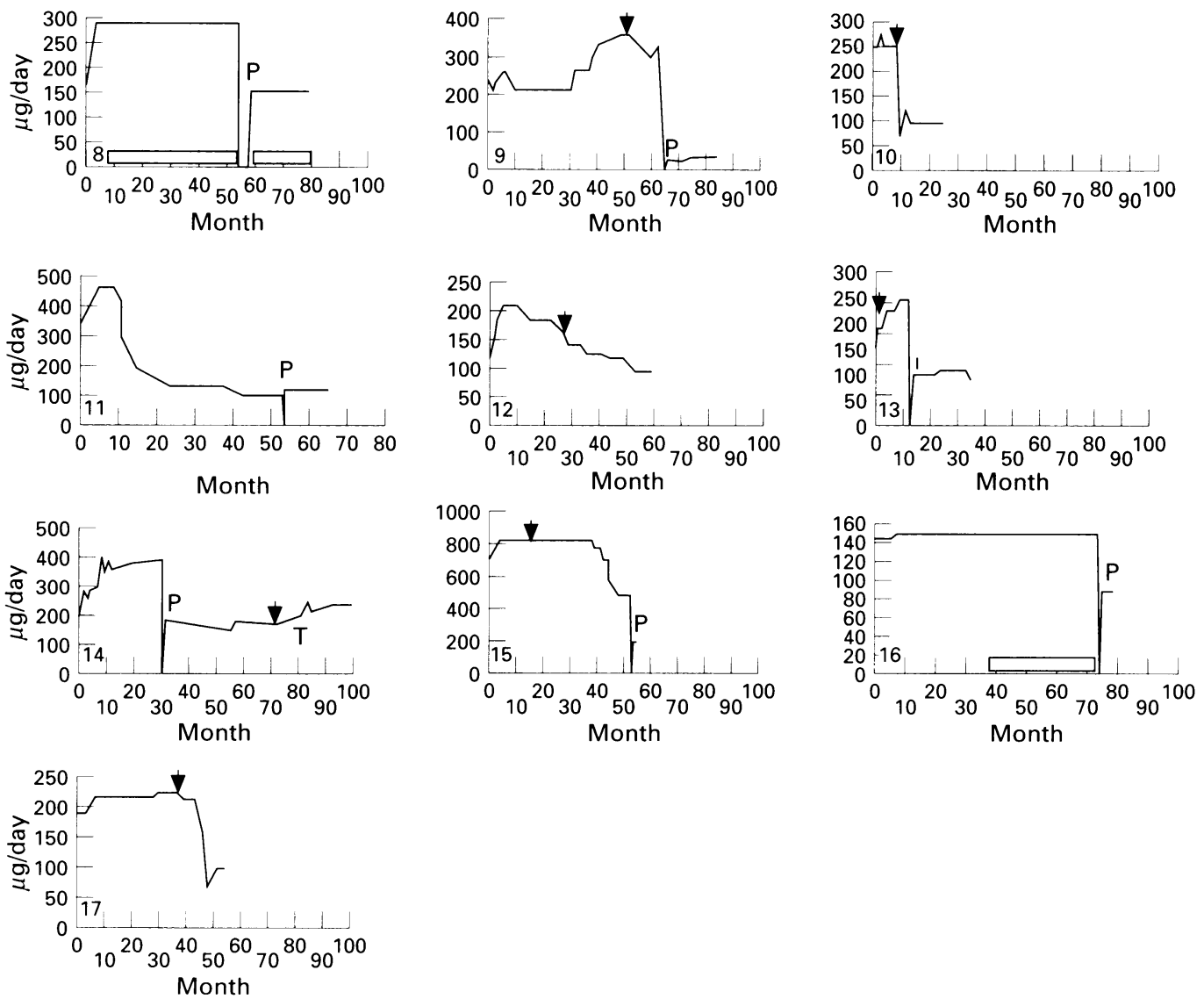
Figure 3 Time course of intrathecal baclofen doses for patients for whom no dose reduction was possible. $M=$ morphine; other abbreviations as fig 1 and fig 2. With patient 25 we tried three times to switch from baclofen to morphine, with little success.
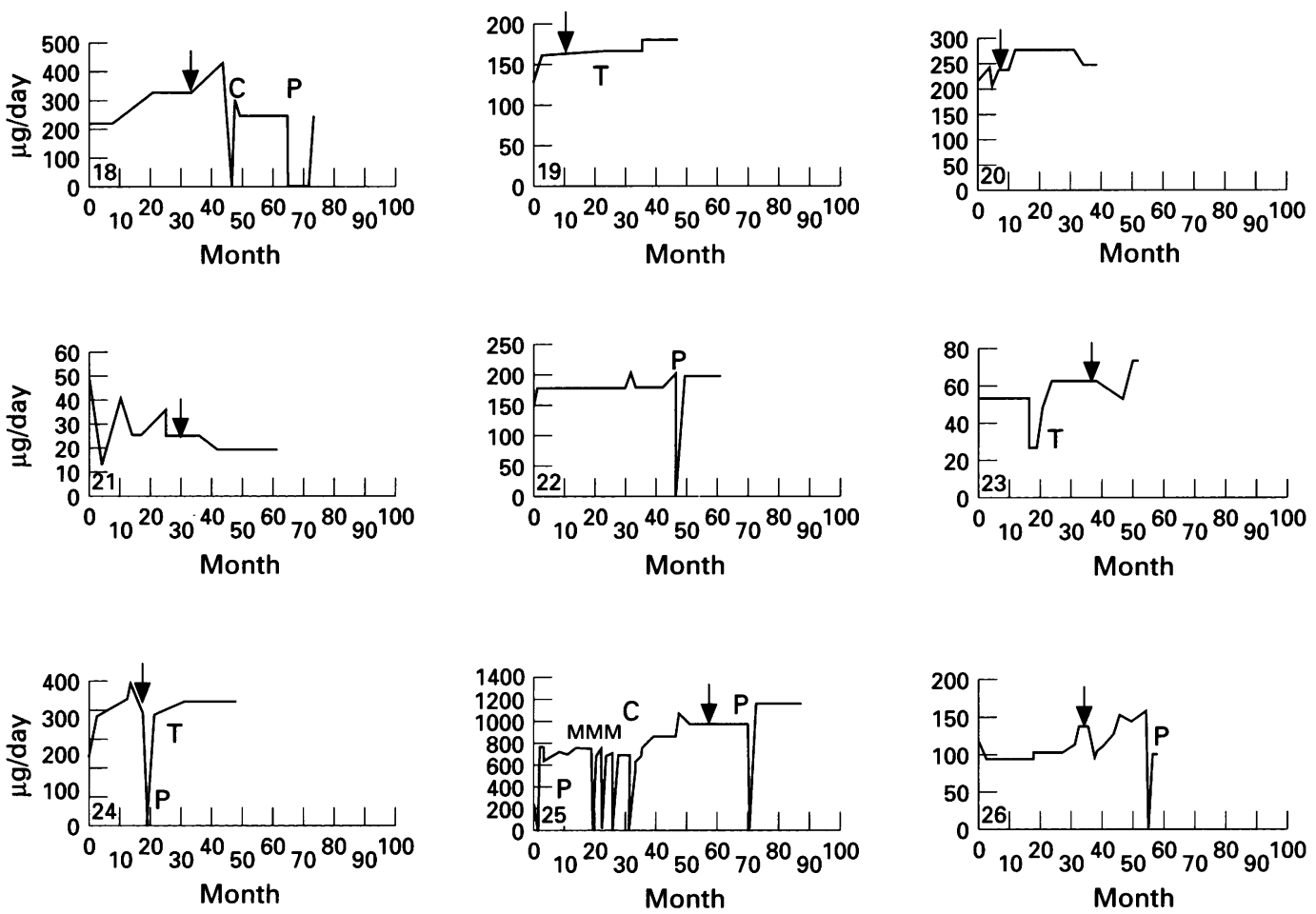

transverse lesion due to a tumour without a measurable increase in spasticity (patients $8-17)$. Dose reduction was tried in small steps in some patients $(11,12,15)$ or in a large step in other patients $(9,10,13,14,16,17)$ when the patients were in hospital because of catheter or pump malfunction or other causes. The dose of baclofen, which was 290 (SD 200) $\mu \mathrm{g} /$ day at the end of the first year, was reduced to 120 (SD 60) $\mu \mathrm{g} /$ day during the last year of treatment (fig 2). The mean duration of treatment of these patients with intrathecal baclofen was 65 (SD 23) months. Within the group of patients in whom the intrathecal baclofen treatment could finally be stopped we tried a reduction in three patients $(3,6,7)$ before stopping the infusion.

Before we became aware of the possibility of reducing the intrathecal baclofen dose after it had remained stable for several months, our policy was to keep the dose at the same level. Thus the value of dose reduction only became obvious while patients $(9,10,13,14,16$, and 17) were staying in hospital, when we titred the necessary dose after restarting the intrathecal infusion. The dose was not changed for patients who had the pumps filled by their general practitioner $(3-5,8,15,16,27)$ until they were admitted to our hospital, primarily for a revision of the pump-catheter system. Only then could we try to readapt the dose to the necessary level.

In some patients there were steep and abrupt changes to a lower or a higher dose.
There were different reasons for this. Patient 9 complained of problems with spasticity at home and thus the dose was increased. After the pump stopped there was again a profound increase of spasticity to 5 on the Ashworth scale. After exchanging the pump without changing the catheter, the muscle tone was reduced to 1 on the Ashworth scale by a dose of $30 \mu \mathrm{g}$.

For patient 14 the dose could be reduced after a change of pump but had to be increased slightly because of increasing spastic symptoms in the upper limbs. After 99 months of treatment with intrathecal baclofen, the patient came one week late for refilling the pump and the treatment had stopped for several days, the muscle tone in the lower limbs had increased moderately to 3 but in the upper limbs it had increased to 5 on the Ashworth scale. With intrathecal baclofen the muscle tone was 1 in the lower limbs and 3 on the Ashworth scale in the upper limbs.

\section{PATIENTS IN WHOM THE DOSE OF}

INTRATHECAL BACLOFEN WAS NOT REDUCED The dose was not reduced in 10 patients (18-27) for various reasons. Increasing spastic symptoms in the upper limbs made it necessary to increase the dose for some patients (19, $23,24)$, in others a reduction of the dose was not possible because of tetraspasticity $(18,20$, 22 ). For patient 25 a reduction trial was made by exchanging baclofen for morphine. While receiving morphine, the patient again devel- 
oped severe spasms within a week so that the treatment with baclofen was restarted. Figure 3 shows that no appreciable dose reduction was possible.

As shown in figs 1,2 , and 3 the intrathecal baclofen dose had to be increased in many patients during the first year of treatment but it tended to remain stable thereafter. During the first two weeks after implantation of the pump the initial dose was titred individually to that level at which there was a reduction of muscle tone to 1-2 on the Ashworth scale in the lower limbs and/or the spasms were reduced to $0-1$ on the spasm scale. When the patients came to have the pump refilled it depended on the clinical examination (muscle tone, spasms, tendon reflexes) whether the dose of intrathecal baclofen remained the same or whether it had to be increased or reduced.

\section{Discussion}

To our knowledge, a lasting reduction of spasticity after ending chronic intrathecal infusion of baclofen has not been reported up to now. Obviously there is great individual variability in the intrathecal baclofen dose which is necessary for reducing spasticity at the beginning of the treatment (for example, 9, 15, 23). Usually a dose is chosen which reduces the muscle tone enough but does not completely suppress the patellar reflex. This regime is chosen to reduce the risk of venous thrombosis due to flaccid paresis. The great interindividual variability of an intrathecal baclofen dose makes it impossible to deduce from the patient group if there is a specific dose which will lead to lasting suppression of spasticity. Neither is it clear whether the infusion of higher than necessary doses will lead to the observed effect faster. It is important to note that the lasting reduction of spasticity or a reduced need for intrathecal baclofen to suppress spasticity was more pronounced in the lower than in the upper limbs in patients with tetraspasticity.

Possible mechanisms for this differential effect could be structural changes at the caudal spinal cord due to mechanical or reactive inflammatory lesions caused by the intraspinal catheter. However, some of our patients who had only an incomplete transsection could still move their legs $(1,15)$ or even walk $(6)$. Thus the hypothesis that mechanical or reactive inflammatory lesions are the primary cause does not explain the findings in all patients.

For patients with multiple sclerosis it is assumed that new inflammatory lesions within the spinal cord lead to a reduction of spinal excitatory circuits and cause spinal spastic symptoms. However, some of those patients who were able to stop treatment $(5,6)$ or who showed an obviously more pronounced effect in the lower limbs than in the upper limbs (8, 18) did not have multiple sclerosis. Thus some other factors must be involved.

Alhough there was obviously muscle atrophy in some patients due to inactivity this cannot be the main reason for the sustained suppression of spastic symptoms, because one of the patients (6) could walk, others $(1,15)$ could voluntarily bend their knees, and in most patients the tendon reflexes reappeared.

Another explanation might be a toxic effect of baclofen on the spinal cord neurons. This would also explain why lasting suppression of spastic symptoms was more pronounced in the lower limbs than in the upper limbs, reflecting a correlation with the concentration of baclofen. The concentration of baclofen in the CSF is four times higher at the lumbothoracic level than at the cervical level when it is given at the lumbothoracic level. ${ }^{11-13}$ But as some of our patients could walk again without showing any deterioration after having received intrathecal baclofen for years, it is unlikely that a toxic effect alone is the reason for the sustained suppression of spasticity. Also, toxicity tests in animals did not show any toxic side effects of intrathecal baclofen. ${ }^{14-16}$

Possibly structural changes are induced by the prolonged influence of highly concentrated baclofen at the spinal level. These may be the result of altered intracellular mechanisms due to long term alterations of second messenger dependent regulators. Baclofen binds to presynaptic and postsynaptic GABA-B receptors ${ }^{17} 18$ and down regulates $\mathrm{Ca}^{2+}$ influx by a protein $\mathrm{G}$ coupled change of $\mathrm{Ca}^{2+}$ channels. ${ }^{18-20}$ Furthermore it is known that protein $G$ dependent second messengers and $\mathrm{Ca}^{2+}$ can regulate gene expression within the nucleus, ${ }^{21}$ and hence long term adaptive changes could occur. The ability of baclofen to cause long lasting adaptive morphological and, hence, physiological changes in spinal neurons has been shown. After repetitive pain stimuli early gene proteins fos, jun, and krox24 are expressed in spinal neurons. These gene expressions can be modulated by morphine, baclofen, and NMDAantagonists. ${ }^{22-25}$ When morphine or baclofen was given before noxious stimuli, an activation of an intracellular cascade activating the nucleus and leading to the expression of immediate early genes could be prevented.

A dose dependent effect can be deduced from the finding that the suppression of spasticity was stronger and more lasting in the lower limbs than in the upper limbs of two patients with tetraspasticity. The concentration of baclofen infused at the lumbothoracic level decreases in a cranial direction (see earlier).

Patient 18 had a sustained suppression of spastic symptoms for six months after the pump had stopped, but there was again a profound increase in muscle tone in the lower and upper limbs after a severe infection. This could indicate that the mechanisms which are responsible for spastic symptoms remained down regulated during the period when there was no incease in spasticity after the pump had stopped but then were upregulated again after an infection. Thus a reversability of the long lasting suppression of spasticity after stopping intrathecal baclofen infusion has to be considered. Whether such a change will also occur in the other seven patients who still do not need intrathecal baclofen remains to be seen.

By contrast with a possible reduction after 
several years of intrathecal baclofen treatment, it is obviously necessary to increase the dose during the first year of treatment. This finding has also been reported by other authors. ${ }^{356}$ The reason for this is not clear. After beginning treatment with intrathecal baclofen there is a down regulation of GABA-B receptors in the spinal cord at least during the first seven days in rats. ${ }^{26}$ No studies have investigated the long term effects at the cellular level. Electrophysiological investigations prove that baclofen binds at lower concentrations to the presynaptic GABA-B receptor in the substantia gelatinosa than to the postsynaptic GABA-B receptor at $\alpha$-motoneurons. ${ }^{27}{ }^{28}$ It can only be speculated whether the down regulation of the GABA-B receptor in the substantia gelatinosa means that it is necessary to increase the dose of baclofen; its binding at the postsynaptic GABA-B receptor on $\alpha$-motoneurons is thus enhanced and the excitability of the $\alpha$ motoneurons is reduced directly. ${ }^{29}$

In conclusion, from a group of 27 patients who received intrathecal baclofen for more than two years, seven patients had sustained suppression of spastic symptoms such as increased muscle tone and spasms after discontinuing intrathecal baclofen. The dose of intrathecal baclofen could be reduced considerably in 10 other patients after a treatment period of more than two years. These findings are possibly explained by long term baclofen induced morphological changes in spinal cord neurons. It could well be that earlier treatment or the use of a higher daily dose of intrathecal baclofen would yield a better and longer lasting suppression of spasticity. Perhaps a preemptive, early treatment with baclofen could also prevent or decrease the development of spastic symptoms such as spasms and increased muscle tone after spinal cord lesions or a sudden paraparesis or monoparesis due to myelitis in an acute bout of multiple sclerosis.

Presently, we recommend trying to reduce the dose of intrathecal baclofen after a constant effective dose has been reached, at least once a year. Treatment with intrathecal baclofen, with all its possible complications, can be terminated in at least some patients.

1 Penn RD, Kroin JS. Intrathecal baclofen alleviates spinal cord spasticity [letter]. Lancet 1984;i:1078

2 Ochs G, Struppler A, Meyerson BA, et al. Intrathecal baclofen for long term treatment of spasticity: a multicentre study. F Neurol Neurosurg Psychiatry 1989;52 933-9.

3 Loubser PG, Narayan RK, Sandin KJ, Donovan WH Russell KID. Continuous infusion of intrathecal baclofen: long-term effects on spasticity in spinal cord injury. Paraplegia 1991;29:48-64.
4 Penn RD. Intrathecal baclofen for spasticity of spinal origin: seven years of experience. $\mathcal{f}$ Neurosurg 1992;77: 236-40.

5 Meythaler JM, Steers WD, Tuel SM, Cross LL, Haworth CS. Continuous intrathecal baclofen in spinal cord spasticity. A prospective study. Am $₹$ Phys Med Rehabil 1992; 71:321-7.

6 Coffey JR, Cahill D, Steers W, et al. Intrathecal baclofen for intractable spasticity of spinal origin: results of a longterm multicenter study. $\mathcal{F}$ Neurosurg 1993;78:226-32.

7 Zierski J, Müller H, Dralle D, Wurdinger T. Implanted pump systems for treatment of spasticity. Acta Neurochir Suppl (Wein) 1988;43:94-9.

8 Dressnandt J, Konstanzer A, Conrad B. Reversal of spasticity after longterm treatment with intrathecal baclofen. $\mathcal{F}$ Neurol 1992;239S3:37

9 Ashworth B. Preliminary trial of carisoprodol in multiple sclerosis. Practitioner 1964;192:540-2.

10 Lee KC, Carson L, Kinnin E, Patterson V. The Ashworth scale: a reliable and reproducible method of measuring spasticity. $\mathcal{F}$ Neurol Rehabil 1989;3:205-9.

11 Kroin JS, Penn RD. Implantable pumps to deliver drugs directly into the CNS. In: Neuwelt EA, ed. Implications of the blood-brain barrier and its manipulation. Vol 2. Clinical the blood-brain barrier and its manipulation. Vol 2 .

12 Sallerin-Caute B, Lazorthes Y, Monsarrat B, Cros J, Bastide R. CSF baclofen levels after intrathecal administration in severe spasticity. Eur f Clin Pharmacol 1991;40: 363-5

13 Kroin JS, Ali A, York M, Penn RD. The distribution of medication along the spinal canal after chronic intrathecal administration. Neurosurgery 1993;33:266.

14 Wilson PR, Yaksh TL. Baclofen is antinociceptive in the spinal intrathecal space of animals. Eur $\mathcal{f}$ Pharmacol 1978;51:323-30

15 Yaksh TL, Reddy R. Studies in the primate on the analgesic effects with the intrathecal actions of opiates, adrenergic agonists and baclofen. Anesthesiology 1981;54: 451-67.

16 Kroin JS, Penn RD, Bessinger RL, Arzbaecher RC. Reduced spinal reflexes following intrathecal baclofen in Reduced spinal reflexes following intrathec

17 Bowery NG, Hill DR, Hudson AL, Doble A, Middlemiss DN, Shaw J, Turnbull M. (-)-Baclofen decreases neurotransmitter release in the mammalian CNS by action at a novel GABA receptor. Nature 1980;283:92-4.

18 Bowery NG, Pratt GD. GABAB receptors as targets for drug action. Arzneimittelforschung 1992;42:215-23.

19 Dolphin AC, Scott RH. Inhibition of calcium currents in cultured rat dorsal root ganglion neurones by (-)baclofen. Br $\mathcal{F}$ Pharmacol 1986;88:213-20.

20 Kangrga I, Jiang $M$, Randic $M$. Actions of (-)-baclofen on rat dorsal horn neurons. Brain Res 1991;562:265-75.

21 Zimmermann H. Synaptic transmission. Cellular and molecular basis. New York: Oxford University Press, 1993:94-104.

22 Castro-Lopes JM, Tavares I, Tölle TR, Coito A, Coimbra A. Increase in GABAergic cells and GABA levels in the A. Increase in GABAergic cells and GABA levels in the
spinal cord in unilateral inflammation of the hindlimb in the rat. Eur $₹$ Neurosci $1992 ; 4: 296-301$.

23 Castro-Lopes JM, Tavares I, Tölle TR, Coimbra A. Carrageenan-induced inflammation of the hind foot provokes a rise of GABA-immunoreactive cells in rat spinal cord that is prevented by peripheral neurectomy or neonatal capsaicin treatment. Pain 1994;56:193-201.

24 Tölle TR, Herdegen T, Schadrack J, Bravo $R$ Zimmermann $M$, Zieglgänsberger W. Application of morphine prior to noxious stimulation differentially modulates expression of Fos, Jun and Krox-24 proteins in rat spinal cord neurons. Neuroscience 1994;58:305-21.

25 Tölle TR, Schadrack J, Castro-Lopes JM, Conrad B, Ziegelgänsberger W. Baclofen reduces immediate-early gene expression in the rat spinal cord following noxious thermal and inflammatory stimulation. 7 Neurol 1995; 242S 2:45.

26 Kroin JS, Bianchi GD, Penn RD. Intrathecal baclofen down-regulates GABAB receptors in the rat substantia gelatinosa. I Neurosurg 1993;79:544-9.

27 Allerton CA, Boden PR, Hill RG. Actions of GABAB agonist, (-)-baclofen, on neurones in deep dorsal horn of the rat spinal cord in vitro. $\mathrm{Br} \mathcal{F}$ Pharmacol 1989;96,29-38.

28 Kangrga I, Jiang $M$, Randic $M$. Actions of $(-)$-baclofen on rat dorsal horn neurons. Brain Res 1991;562,265-75.

29 Dressnandt J, Auer C, Conrad B. Influence of baclofen upon the alpha-motoneuron in spasticity by means of Fwave analysis. Muscle Nerve 1995;18:103-7. 